\title{
Aproximaciones al populismo en Daniel Ortega, Rafael Correa y Nayib Bukele
}

Recibido: 9 de junio de 2021 Revisado: 1 de septiembre de 2021 Aprobado: 12 de noviembre de 2021

José Andrés Díaz González Costarricense. Politólogo. Doctor en Gobierno y Políticas Públicas y Magister en Historia. Es investigador del Instituto de Estudios Sociales en Población (IDESPO) de la Universidad Nacional (Costa Rica), y docente en la Escuela de Ciencias Políticas de la Universidad de Costa Rica (Costa Rica). Trabaja temas relacionados con Cultura política, comportamiento político, gestión y políticas públicas. Correo electrónico: jose.diaz.gonzalez@una.ac.cr ORCID: 0000 0002 6063 086X

César Ulloa Tapia Ecuatoriano. Doctor en Ciencias Sociales por FLACSO Ecuador, Magíster en Ciencias Internacionales (UCE) y Magíster en Gerencia Cultural por la Red UREL

UTE. Docente investigador de la Universidad de Las Américas (Ecuador). Sus líneas de investigación incluyen: política comparada de la región Andina en democracia, populismo. Correo electrónico: cesar.ulloa@udla.edu.ec ORCID: 0000 0002 3631 7494

Sindy Mora Solano

Costarricense. Socióloga. Máster en Derechos Humanos y Educación para la Paz. Es investigadora del Instituto de Estudios Sociales en Población (IDESPO) de la Universidad Nacional (Costa Rica), investigadora del Instituto de Investigaciones Sociales (IIS) de la Universidad de Costa Rica (Costa Rica) y docente en la Escuela de Sociología de esta misma universidad. Trabaja temas relacionados con acciones colectivas, movimientos sociales, memoria de luchas populares, procesos de construcción de resistencias políticas y conservadurismo político.

Correo electrónico: sindy.mora.solano@una.ac.cr ORCID: 0000 0001 6784 5532
Resumen: Las discusiones acerca del populismo evidencian que no es un fenómeno de la política que se origina en un país concreto ni tampoco que las democracias más consolidadas estén exentas de su presencia, pese a que lo consideran como un invitado incómodo. Los ejercicios de comparación entre países, casos y periodos distintos dan cuenta de que se pueden establecer elementos comunes en el sistema político, a manera de causas, las cuales explicarían la emergencia de líderes, partidos y expresiones del populismo. En este artículo, se contrastan los presidentes Daniel Ortega de Nicaragua, Nayib Bukele de El Salvador y el exmandatario Rafael Correa de Ecuador con la finalidad de explicar el contexto de su aparición en el sistema político de sus países.

Palabras clave: Centroamérica, Ecuador, populismo, democracia, sistema político

\section{Approaches to Populism in Daniel Ortega, Rafael Correa and Nayib Bukele}

Abstract: Discussions about populism make it clear that it is not a political phenomenon arising in one country, and that the more wellestablished democracies are not exempt from its occurrence, despite considering at an inconvenient guest. Comparisons between diverse countries, cases, and periods show that common causal elements can be pinpointed in political systems that may explain the emergence of populist leaders, parties, and manifestations. This article contrasts presidents Daniel Ortega of Nicaragua, Nayib Bukele of El Salvador, and former president Rafael Correa of Ecuador to clarify the context of their appearance in their countries' political system.

Key words: Central America, Ecuador, populism, democracy, political system. 
El populismo no es un fenómeno nuevo, durante buena parte del siglo $X X$ ha sido, en el mejor de los casos, un inquilino incómodo en la vida política de los países latinoamericanos. Sin embargo, durante las dos décadas iniciales del siglo XXI, su incidencia en el desarrollo político de la región se ha potenciado, especialmente por la aparición de figuras como Hugo Chávez, Evo Morales y Rafael Correa, todos políticos populistas cuya influencia, ya sea que se considere positiva o negativa, es indiscutible en la región.

Así, Chávez, Morales y Correa han pasado a ubicarse como cierto "arquetipo" del político populista, y la literatura académica dedicada a su estudio es vasta; sin embargo, aún quedan muchas inquietudes y preguntas de investigación alrededor de estas figuras (Borón 2012; Cannon 2018; de la Torre 2018; Ellner 2012; Silber 2013; Ulloa-Tapia 2017). No obstante, estos no son los únicos políticos populistas que han logrado alcanzar la presidencia de sus países durante el siglo XXI en América Latina.

Por tal razón, en el presente artículo y, desde una perspectiva exploratoria, se busca estudiar a dos figuras políticas populistas surgidas en la región centroamericana: Daniel Ortega en Nicaragua y Nayib Bukele en El Salvador; al mismo tiempo que se compara con el caso de una figura más estudiada: Rafael Correa en Ecuador. Dado que la trayectoria política y periodos temporales de dichas figuras son diversas, nos concentramos en comparar el momento en que cada uno fue electo por primera vez como presidente. Así, pretendemos determinar cuánta incidencia pudieron tener sus características como líder populista para alcanzar el control del poder ejecutivo.

La selección de los casos se realiza bajo un criterio de diversidad. En primer lugar, tenemos a un político de amplia trayectoria como Daniel Ortega, el líder histórico de la revolución nicaragüense, quien ya había ocupado la presidencia del país durante la década de los ochenta, pero que regresó al poder en el 2006, apoyándose en una estrategia política populista. En segundo lugar, está el caso de Rafael Correa, un outsider que llega a la presidencia de Ecuador en el 2007 y, desde ahí, se convierte en una de las figuras políticas más visibles e influyentes en Latinoamérica, y cuyo liderazgo populista ha sido ampliamente estudiado.

Por último, el más reciente, Nayib Bukele, electo presidente de El Salvador en el 2019, quien con su juventud, discurso y manejo de redes sociales, ha conseguido proyectar una imagen que le ha permitido obtener la simpatía y el apoyo de un amplio sector de la ciudadanía, y que, aunque se presenta como un outsider, tiene una trayectoria política tradicional; adicionalmente, a diferencia de Ortega y Correa, que se identifican con la izquierda, Bukele, a pesar de provenir de la izquierda tradicional salvadoreña, llega al poder apoyado por una coalición de derecha conservadora.

Por lo tanto, con esta diversidad de trayectorias políticas y contextos, se identifican elementos que ayudan a perfilar las causas del surgimiento y consolidación, al menos desde la perspectiva electoral, de líderes, partidos y ex- 
presiones del populismo, más allá de sus características ideológicas, coyunturales o personales particulares.

Para ello, el presente artículo se divide en cinco apartados. En el primero, se revisa el concepto de populismo y se presentan las características básicas sobre las cuales se identifica el liderazgo de las figuras políticas analizadas como populistas. En el segundo, se expone la metodología que se empleó para el análisis de los casos; asimismo, se explica la selección y operacionalización de la información consultada.

En el tercero, se reconstruyen los contextos sociopolíticos de Nicaragua, Ecuador y El Salvador, al momento de la elección de Ortega, Correa y Bukele, esto con el propósito de identificar los elementos coyunturales similares y diferentes que pudieron incidir en la elección de cada uno de ellos como presidentes. En el cuarto, se expone la trayectoria política y las características personales de Ortega, Correa y Bukele, para identificar cuáles de estos elementos pueden incidir en la consolidación de su liderazgo. Finalmente, se realiza un análisis comparado de los elementos anteriormente expuestos y se presentan las principales conclusiones.

\section{Acercamiento conceptual al populismo}

Desde finales del siglo $\mathrm{XX}$ e inicios del siglo $\mathrm{XXI}$, en diversas partes del mundo, especialmente en Sudamérica, han resurgido una serie de gobiernos populistas (Borón 2012; Bueno Romero 2013; Gratius 2009; Roberts 2007; Ulloa-Tapia 2017). Este resurgimiento del populismo sudamericano se ha visto acompañado por un repunte importante de líderes populistas en Europa (Bugaric y Kuhelj 2018). Incluso Estados Unidos, con la elección de Donald Trump, ha entrado en este ciclo de fortalecimiento del populismo (de la Torre 2017; Hodges 2019; Lynch 2019).

No obstante, a pesar de la vasta literatura académica desarrollada en torno al populismo, como concepto analítico, este ha resultado esquivo y difícil de precisar, generando así un gran número de definiciones y acepciones del término (Fernández Mateo 2012; Sánchez Figuera 2016). De esta manera, en la literatura académica hay una amplia discusión acerca de los alcances, así como sobre la propia definición del término populismo. Incluso algunos trabajos señalan que este concepto se debe ajustar a partir de las características propias de la región, sistema y cultura política del caso que se está analizando (Bueno Romero 2013; Bugaric y Kuhelj 2018; Cannon 2018; Galito 2018).

En términos generales, se tiende a identificar el populismo como un proceso político negativo o dañino que amenaza a las democracias, pues se basa en el fortalecimiento de la figura de un líder, lo cual diluye la representación democrática, al tiempo que se adoptan medidas para excluir las voces disidentes del escenario político. No obstante, otras perspectivas consideran que los gobiernos populistas no necesariamente anulan las democracias, al contrario, en ocasiones amplían los derechos civiles y políticos de la población, 
como parte de un proceso de ensanchamiento de la comunidad política (Hernández y Hurtado 2010; Ulloa-Tapia 2017).

A pesar de la posible faceta democratizadora presente en el populismo, en la literatura académica parece existir un consenso, el cual señala, en el mejor de los casos, que este tiene una relación contradictoria con la democracia. Así, si bien por una parte los gobiernos populistas pueden estar interesados en integrar a los grupos excluidos y vulnerables de la población, fortaleciendo el acceso a sus derechos políticos, sociales y económicos; por otra parte, busca anular la diversidad de actores políticos presentes en la sociedad, al mismo tiempo que debilita los mecanismos políticos de representación y participación popular (Bijukumar 2004; Jansen 2011; Ulloa-Tapia 2017). Por lo tanto, una de las características principales del populismo es que agrupa, tantos elementos democráticos como autoritarios:

El populismo articula ingredientes democráticos y autoritarios: ampliación de la ciudadanía, recurso a procedimientos electorales, pluripartidismo, extensión de la participación social y política, junto con: control vertical de las organizaciones sociales, reducción del espacio institucional para la oposición, promoción de un sistema político ampliado y al mismo tiempo excluyente. (Vásquez 2007, 331)

Adicionalmente, la literatura académica que define el concepto de populismo lo hace a partir de tres esferas principales. La primera, la esfera política, se concentra en observar liderazgos fuertes, personalistas, con capacidad retórica y de motivación de diferentes sectores sociales bajo las consignas de unidad nacional y defensa de la soberanía nacional. La segunda esfera, la económica, analiza las reformas legislativas que promueven políticas proteccionistas e intervencionistas conjugadas con la idea de nacionalismo. Por último, la esfera social genera su contenido a partir del análisis de las reformas sociales que procuran incluir a sectores desfavorecidos o históricamente excluidos, así como las movilizaciones populares como base para la legitimación del poder (Bueno Romero 2013, 213).

El presente artículo analiza la esfera política del populismo, ya que centra su atención en las características del liderazgo político de candidatos que han llegado al poder apoyados en discursos populistas. Por lo tanto, se entenderá populismo como "una estrategia política que logra la movilización social, que el gobernante utiliza como sustento político y de legitimación de su poder; el populismo deviene de un gobernante o individuo - personalista, carismático - y no de un grupo u organización, y emerge cuando estos líderes basan su 
gobierno en estrategias de manipulación de masas" (Bueno Romero, 2013, p. 126).

Por lo tanto, siguiendo la propuesta de Bueno Romero (2013), el populismo, al menos desde su asociación con la esfera política, puede ser estudiado de forma operativa a partir del liderazgo político y el discurso, los cuales se entienden como:

Liderazgo político. Enfoca un líder caracterizado como personalista, carismático, paternalista, cuya imagen y fortaleza impacta en el pueblo. La crítica es la posición de autonomía y legitimidad que logra el líder para decidir en nombre del pueblo, incluso por encima de las instituciones del Estado y sus controles.

Discurso. Entendido como la acción comunicativa que el líder emplea para persuadir. Como todo discurso político, el énfasis está en la división maniquea que polariza "los buenos y los malos", "el pueblo y el antipueblo", entre otros, cautivando y logrando estados mentales y emocionales en las masas o seguidores. (Bueno Romero, 2013, p. 126)

Asimismo, el hecho de que el populismo tenga su base en la figura de un líder carismático ayuda a comprender por qué en los sistemas presidenciales, especialmente en los de América Latina, ha sido tan común el surgimiento de gobiernos populistas. En estos sistemas de gobierno, un gran peso y poder simbólico, legal y político recae en la figura del presidente; lo que lleva a la ciudadanía a esperar que quien ocupa este cargo tenga la capacidad de solucionar un amplio espectro de problemas y situaciones que los aquejan, de tal manera que los discursos de los políticos populistas son atractivos para la población, ya que, en muchos casos, son consecuentes de su forma de entender el funcionamiento del sistema de gobierno presidencialista (Philip 1998; Tedesco y Diamint 2014).

Además, el populismo surge y se consolida en el poder en contextos de crisis institucional y de crisis del sistema de partidos; asimismo, la irrupción del populismo asienta el debilitamiento del sistema institucional y la desaparición acelerada de los partidos. Como expresa Ulloa (2017), el populismo surge como una alternativa cuando los actores políticos presentan incapacidad de recomponer el sistema político: 
[El populismo] se gesta [en] un momento de inmovilidad, en el que los actores se bloquean mutuamente y eso es capitalizado por un tercero en escena que aprovecha el vaciamiento del espacio político y la falta de respuesta de los actores. Por consiguiente, el populismo también es una respuesta frente a la inexistencia de alternativas dentro del sistema. (Ulloa-Tapia, 2017, p. 266)

Por eso, en el presente análisis, se propone realizar dos tareas: la primera, identificar las condiciones sociopolíticas en Nicaragua, Ecuador y El Salvador que permitan explicar la elección de Daniel Ortega, Rafael Correa y Nayib Bukele. La segunda tarea consiste en identificar el tipo de populismo de cada uno de estos políticos, ya que, si bien se puede señalar un concepto básico de populismo que los engloba, diversos autores señalan que existen diferencias y matices en los discursos y posturas de los líderes populistas, las cuales pueden explicar su efectividad en diversos contextos políticos (Blassnig y Wirz 2019; Ulloa- Tapia 2017; Vásquez 2007).

\section{Apartado metodológico}

Hay una vasta literatura de política comparada acerca de América Latina que incluye los viejos y nuevos métodos desde los cuales se abordan distintas agendas y aproximaciones a los elementos del sistema político entre los países. América Latina ha sido vista y comparada desde adentro o de manera intrarregional, pero también por una comunidad de expertos, conocidos como latinoamericanistas, de Europa y los EE. UU. También se ha comparado América Latina con algunos continentes y, dentro de ellos, con sus regiones. Para el caso específico de este artículo, que aborda el populismo en clave comparada, cabe decir que este tipo de ejercicios ha estado presente desde la década de los sesenta (Di Tella 1965; Germani 1962), pero con especial énfasis en los países a los cuales se atribuye el origen del populismo en el Cono Sur, es decir, Argentina y Brasil, debido a figuras como Juan Domingo Perón y Getulio Vargas, quienes gobernaron sus países y dominaron en la escena política por cuatro décadas, respectivamente.

Hay una tendencia a ubicar el populismo como un fenómeno de predominancia en América Latina (lanni 1980), excepto en Costa Rica, Uruguay y Chile. Por su parte, Gratius (2007) habla de las tres olas del populismo: clásico, neopopulismo (década de los noventa) y del socialismo del siglo XXI que incluye a los líderes y sus gobiernos en Venezuela, Ecuador y Bolivia (Gratius 2007). Los estudios del populismo se han enfocado en casos y, últimamente, se analizan de manera comparada dada la "explosión" de varios líderes y gobiernos con características similares en todo el mundo (Judis 2018). 
Pese a la similitud de patrones culturales entre los países de Suramérica y Centroamérica, y de ciertas realidades socioeconómicas, políticas y de cultura política; sin embargo, no se ha registrado una tendencia de investigación que compare a países como Nicaragua, Ecuador, El Salvador, Venezuela o Bolivia, para citar unos cuantos ejemplos acerca del populismo. ${ }^{1}$ No obstante, hay evidencias del análisis de este fenómeno en Centroamérica por cuerdas separadas en Nicaragua bajo el gobierno de Daniel Ortega (Arriola 2009) y en El Salvador con la presencia de Nayib Bukele (Navas 2020).

\section{Diagrama 1. Elementos considerados para el análisis de contexto}
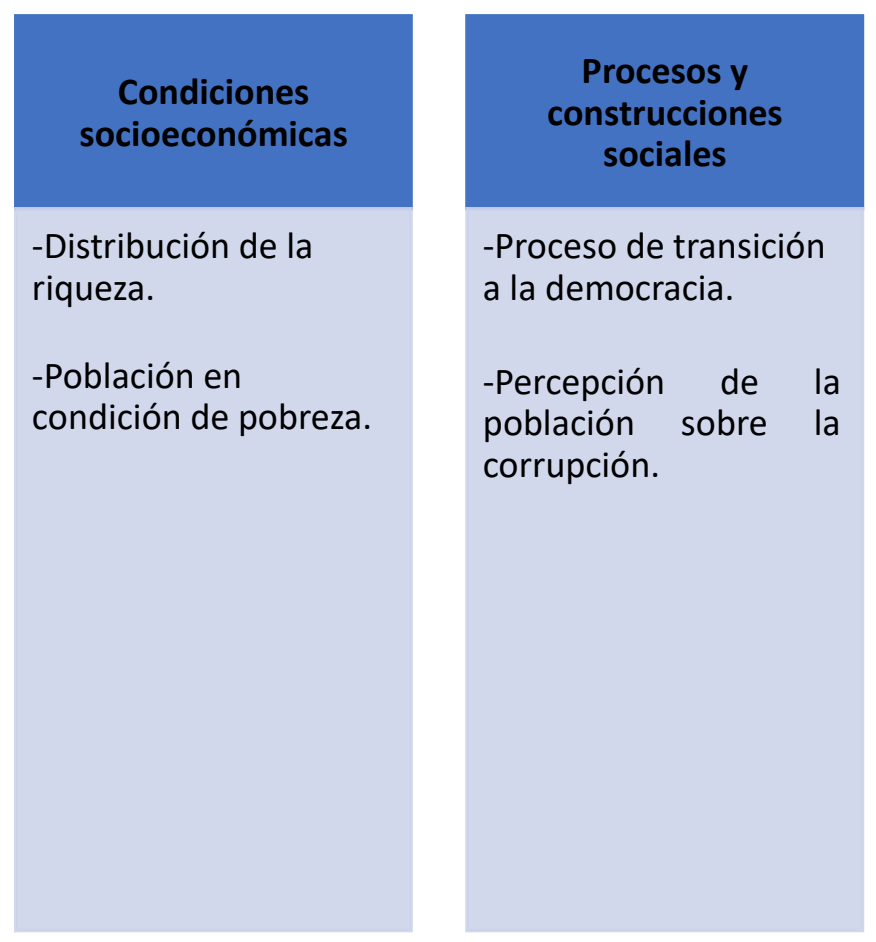

1. Cuando se mencionan los patrones culturales, nos referimos al lenguaje, la religión, las tradiciones y costumbres de herencia hispana, mientras que, al hablar de condiciones socioeconómicas y políticas, se alude a la condición de países en vías de desarrollo, sistemas con altos niveles de fragilidad institucional, a excepción de Costa Rica, y un ambiente creciente de desafección por la política.

Fuente: Elaboración propia (2021).

Dada la similitud de un conjunto de elementos en los sistemas políticos de Nicaragua, Ecuador y El Salvador en las dos últimas décadas, este artículo evidencia que hay un fenómeno como el populismo que atraviesa la realidad de estos países, y ello permite establecer un ejercicio de comparación sin que esto suponga desconocer las propias particularidades. Este análisis, además, posibilita el planteamiento de una agenda de investigación más amplia que supera la construcción de lugares comunes cuando se compara ciertos rasgos de los líderes de los países en mención, pues trata de profundizar en las causas que permitieron la instalación de este fenómeno en los tres países. Alrededor de esta iniciativa surge una posibilidad de trabajar a mediano y largo plazo en una línea de investigación sobre Centroamérica y los países andinos de Suramérica. 
La comparación entre los tres países considera dos grandes dimensiones. La primera de contexto/emergencia del populismo y, la segunda, la caracterización de los líderes que encarnan este fenómeno. La primera se comprende como el "trasfondo social" (Van Dijk 2000) en el sentido de que se identifican y explican las condiciones que atravesaban las instituciones del sistema político de los tres países y sus características institucionales, es decir, cuál es su arquitectura, con la finalidad de establecer semejanzas y diferencias, con el objetivo de presentar ciertos hallazgos que dan cuenta de la emergencia del populismo. La segunda tiene que ver con la caracterización de los personajes en el sentido de identificar, describir y explicar su legitimidad de origen en términos políticos. En otras palabras, existió una trayectoria de "profesionalización de la política”, carisma, así como ciertas prácticas políticas (Weber 1979) de Daniel Ortega, Rafael Correa y Nayib Bukele, o no que haya explicado su éxito.

El análisis de contexto en los tres países (Nicaragua, El Salvador y Ecuador) se circunscribe a la primera elección como presidentes de Nayib Bukele (2019) y Rafael Correa (2007), y la segunda de Daniel Ortega (2007), que corresponde a su retorno al poder. Pese a la distancia entre las elecciones de las tres figuras políticas, hay ciertas similitudes en las condiciones socioeconómicas, elementos del sistema político, procesos y construcciones sociales de los lugares de análisis, los cuales se describen adelante para mayor precisión. Así, si bien estamos comparando casos que ocurren en periodos muy distintos, precisamente, eso nos permite tratar de identificar los elementos y características comunes, que trasciende el contexto temporal, y que ayudan a explicar el surgimiento y consolidación de figuras populistas en la región latinoamericana.

En la tabla 1, se describe y explica cada una de las condiciones sociopolíticas arriba mencionadas y que se utilizan para la comparación del sistema político y económico de los tres países. El objetivo de la selección de estas condiciones es evidenciar cómo estos tres casos, a pesar de que presentan similitudes y diferencias en tiempos, localidades y culturas políticas diferentes; sin embargo, devienen en la misma consecuencia: el populismo. En ese sentido, hay que explorar en mayor profundidad las causas recurrentes o condiciones. 
Tabla 1. Caracterización de las condiciones sociopolíticas

\begin{tabular}{|c|c|}
\hline & \\
\hline Sistema de gobierno & $\begin{array}{l}\text { Identifica el sistema de gobierno de cada país. En } \\
\text { América Latina, el sistema de gobierno imperante es } \\
\text { presidencialista; las características de este facilitan el } \\
\text { surgimiento de figuras populistas. }\end{array}$ \\
\hline $\begin{array}{l}\text { Proc } \\
\text { la de }\end{array}$ & $\begin{array}{l}\text { Tanto Ecuador, El Salvador y Nicaragua sufrieron } \\
\text { distintos tipos de gobiernos autoritarios durante la } \\
\text { segunda mitad del siglo XX, y vivieron procesos de } \\
\text { transición a la democracia desde finales de la década de } \\
\text { los setenta. Observar las características de este proceso } \\
\text { permitirá comprender cuán afianzado está el régimen } \\
\text { democrático en cada país, lo cual se vincula con el } \\
\text { surgimiento de figuras populistas. }\end{array}$ \\
\hline & $\begin{array}{l}\text { isa cómo se percibe la corrupción por parte de la } \\
\text { ón al momento de elegir a Correa, Ortega y } \\
\text {, ya que altos niveles de percepción de corrupción } \\
\text { servir como un indicio de descontento hacia el } \\
\text { ar de instituciones y grupos políticos, al mismo } \\
\text { que pueden facilitar la aceptación de discursos } \\
\text { rupción y antipolítica esgrimidos por figuras } \\
\text { tas. }\end{array}$ \\
\hline & \multirow{5}{*}{$\begin{array}{l}\text { Tanto Correa, Ortega y Bukele llegan al poder mediante } \\
\text { procesos electorales. Si bien, en muchos casos, se } \\
\text { espera que los líderes populistas obtengan un amplio } \\
\text { apoyo popular, esto no necesariamente se traduce en un } \\
\text { fuerte apoyo en las urnas. En ese sentido, resulta } \\
\text { necesario revisar las características del sistema de } \\
\text { partidos, así como el comportamiento del electorado } \\
\text { (volatilidad, competitividad, abstencionismo, votos } \\
\text { obtenidos), para poder visualizar si su elección es } \\
\text { resultado de un fuerte apoyo popular, o bien intervienen } \\
\text { características del sistema electoral de sus países que lo } \\
\text { facilitan. }\end{array}$} \\
\hline elec & \\
\hline Abs & \\
\hline $\begin{array}{l}\text { Porc } \\
\text { obte } \\
\text { las } €\end{array}$ & \\
\hline $\begin{array}{l}\text { Indi } \\
\text { de I }\end{array}$ & \\
\hline & $\begin{array}{l}\text { la democracia, ya } \\
\text { lemocracia podría } \\
\text { s. }\end{array}$ \\
\hline & \multirow{2}{*}{$\begin{array}{l}\text { Altos niveles de pobreza y desigualdad pueden llevar a } \\
\text { grupos importantes de la población a sentirse excluidos } \\
\text { y, con ello, generar un descontento hacia las } \\
\text { instituciones, el gobierno y la clase política en general; } \\
\text { esto puede facilitar el apoyo a líderes populistas. }\end{array}$} \\
\hline & \\
\hline
\end{tabular}

Fuente: Construcción propia (2021).

La decisión de caracterizar a los personajes se explica en el objetivo de evidenciar si los elementos de identidad de los tres líderes configuran el perfil del populista sobre la base de los elementos conceptuales, los que se des- 
agregan de la definición expuesta por Bueno Romero (2013), como se describe y explica en la tabla 2 .

Tabla 2. Características del perfil político

\begin{tabular}{|c|c|}
\hline Elemento & Descripción \\
\hline Tipo de liderazgo & $\begin{array}{l}\text { El liderazgo político populista se apoya principalmente en el } \\
\text { carisma, paternalismo y personalismo de la figura del líder; por } \\
\text { ello, es importante revisar qué características están presentes } \\
\text { en su figura y cómo las utiliza para promoción de su imagen. }\end{array}$ \\
\hline $\begin{array}{l}\text { Trayectoria } \\
\text { (experiencia) } \\
\text { política }\end{array}$ & $\begin{array}{l}\text { El discurso populista tiende a presentar el conflicto político como } \\
\text { una situación de "buenos contra malos", en este último grupo } \\
\text { tienden a colocarse los políticos profesionales o "tradicionales". } \\
\text { Dado ello, muchos líderes populistas tienden a presentarse } \\
\text { como outsiders que no han sido corrompidos por el espacio de } \\
\text { la política. Por lo tanto, es necesario revisar su trayectoria } \\
\text { política para determinar cuál ha sido el proceso que han seguido } \\
\text { para ingresar al espacio político o, en caso contrario, identificar } \\
\text { si tienen una trayectoria política anterior. }\end{array}$ \\
\hline $\begin{array}{ll}\text { Base } & \text { social } \\
\text { apoyo } & \end{array}$ & $\begin{array}{l}\text { El liderazgo político populista se basa en la movilización de } \\
\text { masas o de grupos sociales excluidos, por lo tanto, se revisa si } \\
\text { el candidato cuenta con el apoyo de un grupo o base social, o } \\
\text { bien si busca movilizar a un grupo social específico. }\end{array}$ \\
\hline Ideología & $\begin{array}{l}\text { Las actitudes populistas se ubican en todo el espectro } \\
\text { ideológico, sin embargo, resulta necesario conocer la ideología } \\
\text { que expresa la figura del líder, para así identificar cómo la utiliza } \\
\text { en el desarrollo de su discurso político. }\end{array}$ \\
\hline $\begin{array}{l}\text { Nivel } \\
\text { socioeconómico }\end{array}$ & $\begin{array}{l}\text { Se revisa el nivel socioeconómico del líder para observar si este } \\
\text { se acerca al de las "masas" o grupos sociales a los que no solo } \\
\text { dice representar, sino también pertenecer. }\end{array}$ \\
\hline Profesión & $\begin{array}{l}\text { La profesión del líder puede ayudar a entender el desarrollo de } \\
\text { su trayectoria política, asimismo, puede ser un aspecto } \\
\text { importante para la construcción de su imagen y de su } \\
\text { legitimidad ante los grupos sociales. }\end{array}$ \\
\hline Partido político & $\begin{array}{l}\text { El liderazgo populista es personalista, en consecuencia, el } \\
\text { partido político pasa a un segundo plano, o bien es construido } \\
\text { alrededor de la figura del líder. En ese sentido, es necesario } \\
\text { observar si las características del partido al que le pertenece le } \\
\text { permiten la predominancia de su imagen. }\end{array}$ \\
\hline Discurso & $\begin{array}{l}\text { Polarización. La figura que divide a la población entre el pueblo } \\
\text { y los otros, en donde los últimos son aquellos que están en } \\
\text { contra del líder. Cualquiera puede pasar a la orilla de los otros. } \\
\text { Una crítica al líder es suficiente. Sin embargo, el "todopoderoso } \\
\text { gobernante" tiende a crear enemigos para sobredimensionar su } \\
\text { figura de héroe en permanente batalla contra los enemigos del } \\
\text { pueblo. } \\
\text { Control del Estado. Esta figura se reitera en el discurso del líder, } \\
\text { pues recalca que el favor del pueblo le permite un manejo } \\
\text { discrecional del Estado. El líder es la máxima institución, sobre } \\
\text { las funciones del Estado y las instituciones de la democracia. }\end{array}$ \\
\hline
\end{tabular}

Fuente: Construcción propia (2021). 
El análisis entre las condiciones sociopolíticas y económicas de los tres países en una determinada época y las características de los líderes que emergieron en ese contexto esclarecen la relación entre unas y otras o, mejor dicho, cómo las unas inciden en las otras. Para tener una idea más amplia de lo que sucedía en Nicaragua, Ecuador y El Salvador, se desarrolla en cada caso una explicación de los elementos seleccionados para la comparación.

\section{El populismo en sus contextos}

En este apartado, se analizan los contextos sociopolíticos que hicieron posible la llegada al poder de Daniel Ortega, Rafael Correa y Nayib Bukele. Como se indicó en el apartado metodológico, este artículo enfatiza en el contexto sociopolítico del primer proceso electoral con el que estos líderes llegaron al poder.

\section{Nicaragua: de la revolución a la transformación del FSLN}

Desde mediados de los años noventa, el Frente Sandinista de Liberación Nacional (FSLN) vivió una profunda escisión interna, que marcó los resultados electorales de los años siguientes (Martí I Puig 2016). Si bien Daniel Ortega fue presidente de Nicaragua en el periodo 1985-1990, las elecciones presidenciales de 1990, 1996 y 2001 fueron ganadas por los candidatos opositores al FSLN, el partido de la revolución sandinista. De esta manera, Nicaragua fue gobernada por Violeta Barrios de Chamorro, de la Unión Opositora (UNO), durante el periodo 1990-1997, por Arnoldo Alemán entre 1997 y 2001, y por Enrique Bolaños, durante el 2001 y 2006. Los dos últimos presidentes fueron los candidatos del Partido Liberal Constitucionalista (PLC).

La victoria del FSLN en las elecciones del año 2006, en las que Daniel Ortega retornó al poder, ha sido explicada como el resultado de una serie de factores, entre los cuales destacan los siguientes (Gooren 2010; Martí I Puig 2008): en primer lugar, la firma del acuerdo entre Arnoldo Alemán y Daniel Ortega, en el año 2000, acuerdo conocido como El Pacto, que produjo una reforma a la Ley Electoral, según este se podían ganar las elecciones con el $40 \%$ de los votos o con el $35 \%$ de estos, en caso de que la diferencia entre los candidatos más votados fuese superior al $5 \%$. Esta reforma electoral benefició al Frente que, en la elección del año 2006, obtuvo el $38 \%$ de los votos.

Un segundo factor por considerar fue la transformación en la alienación electoral, que dejó de estar articulada entre el sandinismo y el antisandinismo. Tras la firma de El Pacto se produjo una desarticulación de esta dinámica bipolar, lo que propició el surgimiento de un sandinismo a favor de El Pacto, un antisandinismo en contra El Pacto, un liberalismo a favor y un liberalismo en contra de este. En esta lógica, el sandinismo pactista se vio beneficiado, debido a que el voto duro sandinista se mantuvo fiel al orteguismo, mientras que la oposición se encontraba profundamente dividida. 
El tercer factor corresponde a la transformación de la imagen y el discurso de Daniel Ortega. El líder histórico del FSLN Ilegó al poder con un discurso enfocado en la paz, el amor y la reconciliación política, con lo que invitaba a dejar de lado los tradicionales argumentos centrados en el conflicto de clases y los colores que históricamente caracterizaron al partido: el rojo y el negro. El Frente y su líder, ahora vestidos de rosado, llamaban al voto y a dejar atrás los conflictos sociales que habían articulado a la sociedad nicaragüense. En particular, Daniel Ortega apareció en la campaña política que lo llevó al poder como un hombre de paz y un hijo reconciliado de la iglesia.

Finalmente, el sandinismo que llegó al poder en el año 2006 lo hizo de la mano de la Iglesia católica, al establecer las paces con el cardenal Miguel Obando y Bravo, con el objetivo de incidir en la agenda de los derechos sexuales y reproductivos, en particular, en la regulación del aborto terapéutico, permitido hasta entonces en Nicaragua (Blandón Gadea 2006; Kampwirth 2009). Es importante destacar que las buenas relaciones con actores políticos protestantes también fueron fundamentales en el triunfo electoral de Daniel Ortega en el año 2006 (Gooren 2010).

La campaña política de Daniel Ortega estuvo articulada en torno a las promesas que se vincularon a una política de créditos para los productores, la regulación de las instancias bancarias mediante las cuales llegan las remesas a Nicaragua, debido a la población migrante nicaragüense en el exterior, y el petróleo proveniente de Venezuela (Martí I Puig 2008). Con dichas promesas y con una oposición profundamente dividida, Ortega llegó al poder con un 38 $\%$ de los votos, uno de los porcentajes más bajos obtenido en las elecciones en las que participó el FSLN desde los años noventa (Equipo Nitlápan-Envío 2006a; 2006b).

Las elecciones del 2006 estuvieron marcadas por un abstencionismo del 32 $\%$ del padrón electoral (OEA, 2008) y, de acuerdo con datos provenientes del Latinobarómetro, un $56 \%$ de la población manifestaba apoyo a la democracia para el año 2006 (Corporación Latinobarómetro 2006). Según datos provenientes del Sistema de Integración Centroamericana (SICA), 61,9\% de la población nicaragüense se encontraba en condición de pobreza para el año 2005.

\section{Ecuador: tras la crisis política de una década (1995-2005)}

Ecuador es el primer país de América del Sur en retornar a la democracia en 1979 (Freidenberg y Pachano 2016), en lo que se conoce como la tercera ola de democratización (Huntington 1993). Al igual que la mayoría de los países de la región, estuvo gobernado por dictaduras militares desde inicios de la década de los setenta, después de derrocar a José María Velasco Ibarra en su quinta presidencia (1968-1972). Para varios autores, Velasco fue la figura pionera del populismo ecuatoriano y el actor político más importante del siglo XX (Burbano de Lara 1998; Cuvi 2007; de la Torre 1993; Ojeda Segovia 2013). 
El regreso a la democracia fue negociado entre altos oficiales de las fuerzas armadas y los principales dirigentes de los partidos políticos. Este proceso desembocó en elecciones generales, en las cuales se eligieron los poderes ejecutivo y legislativo, y entre la Constitución de 1945 mejorada o una nueva, al final se eligió una nueva carta constitucional. Para llegar a elecciones, se conformaron comisiones de civiles que elaboraron una nueva ley de elecciones, organizaciones políticas y el diseño institucional del Estado: sistema presidencialista, Congreso unicameral y un aparente moderno sistema de partidos (Hurtado 1998; Pachano 2011; Verdesoto 2014).

El binomio presidencial que ganó las elecciones en la transición y en segunda vuelta fue Jaime Roldós, del partido populista Concentración de Fuerzas Populares (Menéndez-Carrión 1986), y Osvaldo Hurtado de la Democracia Cristiana para el periodo 1979-1984. Roldós falleció en un accidente aéreo en 1981, cuando el sistema político ecuatoriano comenzaba a funcionar con nuevas reglas del juego, en un contexto caracterizado por un conflicto territorial limítrofe con Perú no resuelto desde el año de 1942, el inicio de la década perdida de los ochenta y la pugna entre los principales partidos políticos que se autoproclamaron opositores al Gobierno, en una estrategia utilizada para ganar las elecciones intermedias del Congreso Nacional y desde ahí trazar la ruta para las próximas elecciones. Los primeros años de retorno a la democracia fueron de inestabilidad, pugna de poderes, crisis económica y modernización fallida del sistema político (Verdesoto 2014).

Desde 1979 hasta inicios del nuevo siglo, cuatro fuerzas políticas tomaron el control del Estado en los diferentes gobiernos de turno con una duración de cuatro años en el poder: el derechista Partido Social Cristiano (PSC), el populista Partido Roldosista Ecuatoriano (PRE), el socialdemócrata Izquierda Democrática (ID) y el centroderechista Democracia Popular (DP). Ninguno repitió un mandato, tampoco generaron alianzas para la gobernabilidad y profundizaron el clivaje regional político, pues el PSC y el PRE eran de la costa, mientras que la ID y la DP de la Sierra.

Estos partidos no lograron influencia nacional, pues se localizaron en las principales ciudades del país. Los primeros en Guayaquil, puerto principal, y los segundos, en la capital de la República, Quito. Las tensiones entre las organizaciones fueron frecuentes por la disputa del electorado regional, además de contar con cosmovisiones diferenciadas del país y la forma de administrar los recursos públicos. Las cuatro organizaciones configuraron un sistema multipartidista fragmentado (Paredes Murriagui 2011; Freidenberg y Alcántara 2001), pues convivieron con otros partidos y movimientos que no lograron mayor repercusión.

La pugna de poderes entre el Ejecutivo y el Congreso Nacional fue una regularidad desde 1979 hasta el 2006, pues ningún partido en el Gobierno había logrado una mayoría en el Congreso para viabilizar la aprobación de proyectos de ley. Este fenómeno auspició la configuración de alianzas fantasmas (Burbano de Lara 2005), es decir, negociaciones con poco nivel de sostenibilidad entre las funciones del Estado y los partidos políticos, peor aún acuer- 
dos a más largo plazo (Sánchez López 2008) y, con el tiempo, desconexión entre los partidos y la población (Conaghan 2003; Mejía 2002). Esto contribuyó para que el diseño de políticas públicas se hiciera por fuera de un escenario de pluralidad y más bien con una lógica desde arriba abajo (Mejía 2009). Estas características van de la mano con el criterio de la existencia de zonas grises de la democracia y de la imposibilidad de consolidación de las instituciones que propicien condiciones para mejorar la calidad de vida de la población (O’Donnell 2007).

Entre los años 1995 al 2005, Ecuador atravesó una década de crisis porque se gestaron tres golpes de Estado desde diversas modalidades, pero principalmente en contextos de protesta y movilización popular, decididos en el legislativo y con el tutelaje de las Fuerzas Armadas (Ulloa-Tapia 2017). Autores como Pérez-Liñán (2009) denominan golpes legislativos, pues desde ahí se procesan las figuras normativas que dieron paso a la interrupción del mandato de los presidentes. Para este caso, la caída del líder populista Abdalá Bucaram (1997), después de siete meses de Gobierno, la salida del demócrata popular Jamil Mahuad (2000), después de casi dos años, al igual que del outsider Lucio Gutiérrez (2005). En los tres casos hay un fenómeno de antipolítica, desafección por los partidos y búsqueda de nuevos cuadros emergentes por fuera del sistema. Pese a que Gutiérrez representaba al outsider, coronel golpista en contra del Mahuad y promotor de la refundación del Estado, estos factores no le alcanzaron para que el sistema se estabilizara.

La inestabilidad de esta década posicionó la idea de una nueva política, pero desde un discurso antipartidos, en contra de los líderes históricos y de las viejas prácticas de las negociaciones coyunturales entre estos. En medio de este marco, se produjo la firma de la paz con el Perú en 1998 y se adoptó la dolarización después de que colapsó el sistema bancario y financiero. A la escena saltaron dos nuevos partidos: el PRIAN, del multimillonario bananero Álvaro Noboa, y la Sociedad Patriótica (SP) de Lucio Gutiérrez, pero no pudieron suplantar a los cuatro partidos tradicionales que querían mantenerse, mientras emergía una nueva fuerza social que daría paso al movimiento Alianza PAÍS de Rafael Correa, profesor universitario que había tenido su paso por noventa días en la cartera de Economía como ministro de Estado.

Anterior a la elección de Rafael Correa, en el año 2006, el $54 \%$ de la población apoyaba la democracia (Corporación Latinobarómetro 2007) y un $36.7 \%$ estaba en condición de pobreza. Pese a que no se determina causalidad ni tampoco correlación, las cifras nos indican que casi la mitad de la población no creía en este tipo de régimen y que casi cuatro de cada diez ecuatorianos tenían como prioridad resolver los problemas de primera necesidad, en otras palabras, la gente pedía un cambio. Para las elecciones que dieron el triunfo al candidato de Alianza PAís, se registró un $27.5 \%$ de abstencionismo en un escenario de voto obligatorio. 


\section{El Salvador: de la guerra civil a una democracia frágil}

En febrero de 1972, se gestó un fraude electoral propiciado por el partido de Gobierno. Este evento generó una ruptura y debilitamiento del sistema electoral de El Salvador, el cual, junto a la inestabilidad política y económica que vivía el país desde finales de la década de los sesenta, sirvió de antesala para explicar el golpe de Estado que los militares salvadoreños llevaron a cabo en 1979, y el cual marca el inicio de la guerra civil. Esta guerra finaliza hasta los acuerdos de paz firmados en 1992, y que permiten el paso a un proceso de transición democrática que se consolida con las elecciones de 1994 (Turcios 1997).

Tras la finalización de la guerra civil, y con la reinstalación de procesos electorales que pueden considerarse competitivos, en El Salvador se instala, entre 1997 y el 2019, un sistema electoral bipartidista, dominado por dos fuerzas políticas: la Alianza Republicana Nacionalista (ARENA), de tendencia centroderecha, y la antigua guerrilla del Frente Farabundo Martí para la Liberación Nacional (FMLN), de tendencia de izquierda. Así, ARENA ganó las elecciones presidenciales de 1994, 1999 y 2005, pudiendo considerarse el partido dominante en el periodo de pos guerra civil. Por su parte, el FMLN ganó las elecciones presidenciales por un estrecho margen en el 2009 y volvió a ganarlas en el balotaje de las elecciones del 2014. En el caso de las elecciones legislativas, tanto ARENA como el FMLN han obtenido la mayoría de los escaños, aunque han tenido presencia de partidos minoritarios y, en diversas ocasiones, no han contado con mayorías parlamentarias (Almeida 2016; Malamud y Núñez 2019).

El fin de la guerra civil en El Salvador no significó una disminución de la violencia y los conflictos armados. Desde finales de la década de 1990, la aparición de las "maras" Ilevó a un escalamiento de la violencia en este país centroamericano y, durante las dos primeras décadas del siglo XXI, se ha convertido en una de las zonas más violentas del mundo. Esta situación ha llevado a que las autoridades de Gobierno, sin importar su partido político, promuevan políticas de seguridad de "mano dura", las que han sido poco efectivas para disminuir la violencia y restar poder a estas agrupaciones, las cuales, en muchos casos, han desplazado al Estado y controlan distintos segmentos del territorio salvadoreño (Hernández-Anzora 2016).

A la anterior situación, se le debe sumar que, para inicios del siglo XXI, El Salvador presentaba un rezago importante en el nivel de desarrollo humano, en comparación con otros países latinoamericanos, producto de los conflictos políticos, económicos y armados que vivió desde la década de 1970 (PNUD 2003). Así, entre 1992 y el 2012, la pobreza en El Salvador disminuyó cerca de un $24 \%$, provocada principalmente por el crecimiento económico que tuvo el país en dicho periodo, pero también contribuyeron factores como el aumento del nivel de escolaridad de la población, la disminución del número de miembros promedio por hogar y el aumento de remesas enviadas por migrantes salvadoreños, entre otros (Tijerina y Muñoz 2015). 
A pesar de que El Salvador tiene una tendencia casi constante, desde inicios de la década de 1990, de disminución de la población en condición de pobreza, datos de la Dirección General de Estadística y Censos (DIGESTYC) del Ministerio de Economía (MINEC) indican que, para el 2018, un $26.3 \%$ de los hogares salvadoreños vivían en condiciones de pobreza; eso representa cerca de 2 millones de habitantes, de los cuales casi quinientos mil se encuentran en condición de pobreza extrema (Segura 2019).

Por último, es necesario indicar que la población de El Salvador mantiene una baja afección hacia la democracia, así como una débil institucionalidad político-electoral. Según datos del Latinobarómetro, para el 2018, solo el 28 $\%$ de la población manifestaba apoyar la democracia; y solo un $6 \%$ indicaba tener confianza en los partidos políticos. Asimismo, el Î́ndice del Estado Global de la Democracia, señalaba que tenía un desempeño de "rango medio" (0.71) en lo referente al desempeño del gobierno representativo (IDEA 2020, 119).

En cuanto a las elecciones del 2019, estas estuvieron caracterizadas por un abstencionismo de cerca del $48 \%$ del electorado; asimismo, el nivel de volatilidad electoral fue de casi el $54 \%$. Estos datos parecen consistentes con una población disgustada y decepcionada, tanto con la política como con los partidos políticos tradicionales. Este contexto parece haber beneficiado las aspiraciones electorales de Bukele, quien alcanzó la presidencia con el $53 \%$ de los votos válidamente emitidos. 
Tabla 3. Caracterización de las condiciones sociopolíticas

\begin{tabular}{|c|c|c|c|}
\hline Elemento & $\begin{array}{c}\text { Ecuador } \\
\text { (Elección 2006) }\end{array}$ & $\begin{array}{c}\text { Nicaragua } \\
\text { (Elección 2006) }\end{array}$ & $\begin{array}{c}\text { El Salvador } \\
\text { (Elección 2019) }\end{array}$ \\
\hline Sistema de gobierno & Presidencialista & Presidencialista & Presidencialista \\
\hline $\begin{array}{l}\text { Proceso de transición a la } \\
\text { democracia }\end{array}$ & $\begin{array}{l}\text { A partir de 1979, como parte de } \\
\text { la "tercera ola" de } \\
\text { democratización en América } \\
\text { Latina. }\end{array}$ & $\begin{array}{l}\text { En 1979, finaliza la dictadura de } \\
\text { Anastasio Somoza, el proceso se } \\
\text { consolida hasta } 1990 \text {, como parte } \\
\text { de la "tercera ola" de } \\
\text { democratización en América Latina. }\end{array}$ & $\begin{array}{l}\text { A partir de 1992, se consolida el } \\
\text { proceso, como parte tardía de la } \\
\text { "tercera ola" de democratización en } \\
\text { América Latina. }\end{array}$ \\
\hline $\begin{array}{l}\text { Índice de } \\
\text { Corrupción }\end{array}$ & $\begin{array}{l}\text { N. } 23 \text { en el mundo según el } \\
\text { IPC (2006). }\end{array}$ & $\begin{array}{l}\text { N. }{ }^{\circ} 26 \text { en el mundo según el IPC } \\
(2006) \text {. }\end{array}$ & $\begin{array}{l}N^{\circ} 35 \text { en el mundo según el IPC } \\
(2018) \text {. }\end{array}$ \\
\hline $\begin{array}{l}\text { Características del sistema } \\
\text { de partido }\end{array}$ & Multipartidista fragmentado & Unipartidista (Dominio del FSLN) ${ }^{* *}$ & $\begin{array}{l}\text { Multipartidista } \text { moderado } \\
\text { consolidado) }\end{array}$ \\
\hline Nivel de volatilidad electoral & $42.20 \%$ & $35.56 \%$ & $53.87 \%$ \\
\hline $\begin{array}{l}\text { Nivel de competitividad } \\
\text { electoral }\end{array}$ & 3.99 \% (Primera vuelta) & $9.07 \%$ & $21.38 \%$ \\
\hline Abstencionismo & $27.8 \%$ & $32 \%$ & $48.12 \%$ \\
\hline $\begin{array}{l}\text { Porcentajes de votos } \\
\text { obtenidos para ganar las } \\
\text { elecciones presidenciales }\end{array}$ & $56.67 \%$ (Segunda vuelta) & $38 \%$ & 53.1 \% (Votos válidos) \\
\hline $\begin{array}{lll}\text { Indicador de } & \text { Gobierno } \\
\text { Representativo } & \\
\end{array}$ & $0.81(2006)$ & $0.63(2006)$ & $0.71(2019)$ \\
\hline $\begin{array}{lcccc}\begin{array}{l}\text { Nivel de } \\
\text { democracia }\end{array} & \text { apoyo } & \text { a } & \text { la } \\
\end{array}$ & $54 \%(2006)$ & $56 \%(2006)$ & $28 \%(2018)$ \\
\hline $\begin{array}{l}\text { Distribución de la riqueza } \\
\text { (Coeficiente de Gini) }\end{array}$ & $0.53(2007)$ & $0.48(2005)$ & $0.38(2018)$ \\
\hline $\begin{array}{l}\text { Población en condición de } \\
\text { pobreza }\end{array}$ & $36.7 \%(2007)$ & $48.3 \%(2005)$ & $29.2 \%(2017)$ \\
\hline \multicolumn{4}{|c|}{$\begin{array}{l}\text { Fuente: Construcción propia (2021). Los datos electorales son tomados de las autoridades electorales de Ecuador, Nicaragua y El Salvador. El Índice de Percepción de } \\
\text { Corrupción es tomado de Transparencia Internacional (https://www.transparency.org). El Indicador de Gobierno Representativo es tomado del Instituto Internacional } \\
\text { para la Democracia y la Asistencia Electoral (https://www.idea.int). El coeficiente de Gini y los porcentajes de población en condición de pobreza son tomados del } \\
\text { Banco Mundial (https:///www.bancomundial.org/) } \\
\text { "Los datos expuestos en la tabla buscan caracterizar las condiciones sociopolíticas de los países al momento de la elección de Rafael Correa (2006), Daniel Ortega (2006) y Nayib } \\
\text { Bukele (2019), por lo que se recurre a los datos disponibles más cercanos al momento de la elección. }\end{array}$} \\
\hline
\end{tabular}




\section{Perfilando el liderazgo populista}

Luego de haber expuesto el contexto sociopolítico en el que surgieron los líderes populistas estudiados, en este apartado se expone una caracterización de cada uno de los líderes, con el objetivo de perfilar el tipo de populismo expresado en las figuras de Daniel Ortega, Rafael Correa y Nayib Bukele.

\section{Caracterización de Daniel Ortega}

Daniel Ortega puede clasificarse como un político por vocación (Weber 1979). Durante las décadas de los sesenta y setenta, vivió en la clandestinidad, como comandante guerrillero del Frente Sandinista de Liberación Nacional (FSLN), partido fundado en los años sesenta en la lucha contra la dictadura de los Somoza. Después del proceso revolucionario de 1979, Ortega llegó a la presidencia de Nicaragua en cuatro ocasiones, los últimos tres periodos han sido consecutivos desde el año 2006.

Históricamente, el líder de la revolución sandinista tuvo un apoyo popular, que se encontraba vinculado al apoyo otorgado al Frente Sandinista de Liberación Nacional (FSLN). El control autoritario del partido por parte de Ortega hizo que, en los años noventa, se produjera una importante ruptura en el Frente, en donde líderes históricos como Dora María Téllez y Sergio Ramírez abandonaron el partido (Ramírez 1999). En 1995, estos actores, junto con Gioconda Belli y Henri Ruiz formaron el partido Movimiento Renovador Sandinista (MRS) (Gooren 2010). Con la conformación de este nuevo partido político, el orteguismo tomó el control absoluto del Frente sin que existiera un mínimo espacio para la crítica o la disidencia.

Desde su juventud, Ortega se caracterizó por ser un hombre religioso, en particular, adscrito al catolicismo, pero al mismo tiempo, "interesado en el Protestantismo" (Gooren 2010, 54). Por eso, se señala que la transformación en la imagen y el discurso del orteguismo en las elecciones del 2006 fue parte de una estrategia política que intentó capitalizar la religiosidad ya conocida de Daniel Ortega. Valga señalar que esta estrategia ya se había planteado en el proceso electoral del 2001, con el acercamiento del orteguismo a líderes de iglesias protestantes; sin embargo, en ese momento, esa maniobra política no surtió efecto.

Una figura que se posicionó con fuerza a la llegada al poder de Ortega a partir del año 2006 fue la de su esposa, Rosario Murillo, con quien contrajo matrimonio en el año 2005, justo antes de las elecciones. La boda, celebrada por el cardenal Obando y Bravo, a pesar de que Murillo ha sido la compañera de Ortega por décadas y es la madre de sus hijos, fue sumamente criticada, ya que se consideró parte de la estrategia política que llevó a la pareja al poder. En el marco de esta elección, Ortega fue cuestionado debido a que colocó a Rosario Murillo en la fórmula presidencial, como primera dama y vicepresidenta de la República (Rocha 2016), lo que hace imposible, hasta el día 
de hoy, que se piense en Daniel Ortega sin pensar en su esposa y compañera política.

Actualmente, los hijos de la pareja presidencial se presentan como empresarios, dueños de radioemisoras, canales de televisión y publicidad, que se encargan del proselitismo del régimen Ortega-Murillo (Miranda y Álvarez 2016), por eso muchos han señalado que en Nicaragua se configura una nueva dinastía familiar.

\section{Caracterización de Rafael Correa}

La emergencia de Rafael Correa en la política y su llegada al poder, en el 2007 , se produjo en un contexto de crisis política, no así económica. La fragilidad de las instituciones no había sido resuelta después de la década de ingobernabilidad entre los años de 1995 al 2005; al contrario, el sistema político estaba más debilitado. Los partidos tradicionales atravesaban una época que pasó del declive electoral al colapso y desaparición. La proclama de la antipolítica y el advenimiento de los outsiders se instaló, desde el 2003, con mayor fuerza cuando el coronel Lucio Gutiérrez, quien protagonizó el último golpe de Estado contra el expresidente Jamil Mahuad en el 2000 fue electo primer mandatario. Rafael Correa pertenece a la especie de los outsiders, pues no registra actividad partidista ni trayectoria en la función pública, apenas fue ministro de Economía en el 2005 por noventa días.

Rafael Correa se presentó como el candidato antisistema (Ulloa-2017), de corte carismático (Weber 1979), que se autodefine como un hombre de izquierda, pero que utiliza todo su bagaje técnico, es decir, de doctor en economía y con estudios en el extranjero, para presentarse como ese sujeto culto que, a diferencia de las elites, sí puede establecer una relación con el pueblo (de la Torre 2013). Era la primera vez que competía en elecciones por el cargo más importante del Estado, su respaldo es un paso corto por el Ministerio de Economía. Su candidatura fue apoyada por el movimiento político Alianza PAÍS (Patria Altiva i Soberana) que integraba colectivos y personas de las más diversas variantes ideológicas, desde la derecha, pasando por el populismo hasta la extrema izquierda. Con el tiempo, la mixtura de criterios dio paso al Buen Vivir o el eje vertebrador de la política del discurso de Correa. Esta mixtura es una especie de pirueta ideológica que combina todo y nada (Bretón Solo de Zaldívar, Cortez, y Serrano 2014).

El movimiento PAís había sido creado para las elecciones, sin embargo, en la dirigencia se encontraban figuras históricas de la izquierda ecuatoriana que se habían ubicado en la defensa de los derechos humanos, el medio ambiente, la crítica constante y acérrima contra los organismos multilaterales de crédito y la política internacional de los EE. UU. Dicho sea de paso, ninguno de estos movimientos y personajes antisistema habían llegado al poder. Por lo tanto, no había experiencia en el Gobierno. Sí hubo aspiraciones de quienes lideraban Alianza PAís para llegar al poder y poner en práctica esos pos- 
tulados de izquierda que no se habían concretado desde la transición a la democracia en 1979.

Correa no representaba a las élites económicas y políticas del país, pues su procedencia socioeconómica es de una clase media en ascenso, que tiene entre sus objetivos la preparación académica y destacar en la sociedad desde su rol de manera autónoma. El expresidente estaba dedicado a la docencia universitaria antes de ser gobernante y contaba, entre sus experiencias vitales, haber sido boy scout, dirigente estudiantil en la Universidad Católica de Guayaquil, misionero en pueblos indígenas de la Sierra, becario en universidades de Bélgica y EE. UU. Este relato generó la imagen de un sujeto que proviene del pueblo y que se merece gobernar porque cuenta con las credenciales que la gente quiere. A diferencia de sus contrincantes, la campaña electoral de Correa potenció el uso de los medios, las tecnologías de la información y la comunicación y la propaganda con nuevos recursos que capitalizaron el descontento social con la política y los partidos.

\section{Caracterización de Nayib Bukele}

En el 2017, la revista People publicó una semblanza, bastante positiva y halagadora, de Nayib Bukele, quien en ese momento se desempeñaba como alcalde de San Salvador, y lo etiquetaba como uno de los "líderes de la siguiente generación", debido a sus políticas de cambio cultural como estrategia para combatir la violencia generada por las maras (Dockterman et al. 2017). Tras su victoria en las elecciones presidenciales del 2019, diversos analistas la clasificaron como "histórica", primero, por marcar una ruptura con el bipartidismo tradicional imperante en El Salvador por casi tres décadas y, segundo, porque encontraban en sus ideas "pragmáticas", que buscaban alejarse del debate ideológico de derecha e izquierda, una oportunidad para que el país fortaleciera su institucionalidad y superara los problemas de corrupción y violencia que afectan a esta nación centroamericana. Apoyados en este último punto, desdeñaban las críticas lanzadas hacia Bukele en su campaña, incluso, aquellas que lo identificaban como un populista (Ghitis 2019; Swift 2019; Wade 2019).

Sin embargo, menos de un año después de su elección, quedaba claro el estilo populista de Bukele (Radio Cable 2020), así como sus actitudes autoritarias y el irrespeto a la institucionalidad salvadoreña, al punto de que los mismos analistas que en un inicio veían con esperanza su elección, empezaron a mostrar preocupación y adoptar una actitud más crítica hacia su mandato (Ghitis 2019; 2020). Tras tomar el poder, Bukele ha continuado con la estrategia de utilizar vigorosamente las redes sociales, en especial Twitter, para realizar propaganda, girar órdenes a los miembros de su administración y atacar a sus opositores. Así, parece que el presidente salvadoreño no solo se centra en fortalecer su imagen, sino que su intención ha sido la de desarrollar la "marca Bukele", a partir de la cual ha podido generar empatía y apoyo de un alto porcentaje de la población salvadoreña (Mizrahi 2019; Navas 2020; RuizAlba y Mancinas-Chávez 2020). 
Una segunda estrategia utilizada por Bukele durante su mandato es la de atacar a los medios que publican información crítica a su administración. Tanto Trump como Bukele dirigen sus ataques a medios y periodistas que consideran "sus enemigos" a través de las redes sociales; pero en el caso del segundo, este ha llegado a promover investigaciones contra medios que publican información no favorable a su administración, acusándolos de evasión fiscal y lavado de dinero (Deutsche Welle 2020; El Faro 2020; Guzmán 2020; Wallace 2020).

Una tercera estrategia desarrollada por Bukele es el uso del "cristianismo" para ganar legitimidad. Así, el presidente salvadoreño ha mantenido fuertes vínculos con líderes evangélicos salvadoreños y ha manifestado estar en contra del aborto y los derechos de la población sexualmente diversa (Lobo 2020; Montaner 2020). Asimismo, en una reunión sostenida con pastores evangélicos, señaló que su carrera política, incluido el ser alcalde de San Salvador, presidente de la República y otro cargo "que aún no le sería revelado", le habían sido profetizados por diferentes pastores (Nochez 2020). Es necesario indicar que el vínculo entre políticos y grupos evangélicos en El Salvador no es una estrategia nueva, y ha sido utilizada por los partidos políticos tradicionales anteriormente; sin embargo, un elemento que distingue a Bukele de sus antecesores es que en sus redes sociales ha usado lenguajes religiosos de forma tal que ha construido una imagen de "Mesías" (Marroquín, Menjívar y Ramírez 2020).

Una última estrategia utilizada por Bukele ha sido recurrir al desarrollo de discurso anticorrupción, utilizado desde la campaña política, que le ha permitido polarizar a la población entre los "buenos" (honestos) y los "malos" (corruptos). A manera ilustrativa, durante la campaña política, Bukele acuñó la frase "el dinero alcanza cuando nadie roba"; con lo cual expresaba que, en su gobierno, al eliminar la corrupción, tendría los recursos necesarios para hacer frente a los problemas de la sociedad salvadoreña. 
Tabla 4. Características del perfil político

\begin{tabular}{|c|c|c|c|}
\hline Elemento & $\begin{array}{l}\text { Rafael Correa } \\
\text { Ecuador }\end{array}$ & $\begin{array}{l}\text { Daniel Ortega } \\
\text { Nicaragua }\end{array}$ & $\begin{array}{l}\text { Nayib Bukele } \\
\text { EI Salvador }\end{array}$ \\
\hline Tipo de liderazgo & Carismático & Tradicional & Carismático \\
\hline Trayectoria (experiencia) política & $\begin{array}{l}\text { Exministro de Economía por } 90 \\
\text { días en el gobierno de Alfredo } \\
\text { Palacio (2006). }\end{array}$ & $\begin{array}{l}\text { Excomandante guerrillero, del } \\
\text { Frente de Liberación Nacional } \\
\text { Sandinista y expresidente de } \\
\text { Nicaragua. }\end{array}$ & $\begin{array}{l}\text { Alcalde de Nuevo Cuscatlán } \\
(1 / 05 / 2012-30 / 04 / 2015) \text { y } \\
\text { alcalde de San Salvador } \\
(1 / 05 / 2015-30 / 04 / 2018) \text {. }\end{array}$ \\
\hline Base social de apoyo & Multiclasista. & $\begin{array}{l}\text { Tradicionalmente apoyado por } \\
\text { una base "popular" asociada al } \\
\text { FSLN. }\end{array}$ & \\
\hline Ideología & Izquierda. & Izquierda. & Derecha. \\
\hline Estatus socioeconómico & Clase media. & $\begin{array}{l}\text { Origen nivel socioeconómico } \\
\text { bajo. Actualmente ligado a } \\
\text { empresas de medios de } \\
\text { comunicación. }\end{array}$ & Nivel socioeconómico alto. \\
\hline Profesión & Economista y docente universitario. & $\begin{array}{l}\text { Excomandante guerrillero y } \\
\text { político. }\end{array}$ & Empresario (Publicidad). \\
\hline Partido político & $\begin{array}{l}\text { Partido Alianza PAÍS, que se } \\
\text { construye alrededor de su figura. }\end{array}$ & FSLN. & $\begin{array}{l}\text { Inicia su carrera política en un } \\
\text { partido de izquierda (FMLN), } \\
\text { pero lo abandona y se une a } \\
\text { una coalición conservadora de } \\
\text { derecha (GANA). }\end{array}$ \\
\hline
\end{tabular}

Fuente: Construcción propia (2021). 


\section{Discusión y cierre}

El populismo no tiene como condición suficiente un tipo de liderazgo carismático ni tampoco la de patear el tablero electoral por medio de un personaje que sea considerado outsider. Para los tres casos de estudio, Daniel Ortega es un político de vocación y, más bien, se consolida como un líder de contexto que construyó su imagen, antes de ascender al poder como presidente, como protagonista del proceso insurgente del FSLN. En ese sentido, hay una trayectoria que combina elementos de autoridad jerárquica y la lucha por un conjunto de ideas en contra de la dictadura de su país. Tanto Nayib Bukele como Rafael Correa son líderes carismáticos, pero con trayectorias políticas distintas: en el caso del primero, se evidencia una carrera de profesionalización de la política en el partido FMLN, desde donde llegar a ser alcalde y luego utiliza esa trayectoria para generar una nueva tienda política contraria al bipartidismo predominante en El Salvador. En el caso de Rafael Correa, a diferencia de sus pares, no hay trayectoria política ni tampoco evidencias de protagonismo en algún espacio que le hubiese generado notoriedad pública. Emerge en la escena como un líder por fuera del sistema que pudo estar al frente de la cartera de Economía por un tiempo muy corto, situación que le catapultó en grupos sociales de izquierda.

En los tres casos, tampoco se evidencian elementos comunes en su legitimidad de origen ni tampoco en su trayectoria personal. Los tres líderes provienen de sectores muy distintos: la insurgencia (Ortega), la profesionalización de la política partidista (Bukele) y la oportunidad de un contexto histórico favorable para un nuevo liderazgo (Correa). Tampoco hay un rasgo ideológico que les pudiera acercar, pues, en el caso de Ortega, su imagen se construyó en un contexto de conflicto para retornar a la democracia en el primer momento, mientras que sus pares compiten con las reglas de la democracia en una época de hastío en contra de la gestión de los partidos políticos en sus países. En el caso de Bukele, su estrategia se enfiló en contra del bipartidismo y, en el de Correa, contra el multipartidismo fragmentado. Este discurso en contra del sistema institucional sí es una condición necesaria del populismo, pues si no hay un ataque sistemático en contra del statu quo no serviría de nada la consigna de refundación de la patria y la de crear un nuevo orden para quienes expresan un sentido de descrédito y apatía por el sistema político.

Tampoco se observa que sea una condición suficiente para que se produzca el populismo el origen socioeconómico de los líderes, pero eso no les limita ni condiciona para autodenominarse como candidatos del pueblo. Incluso utilizan la figura del pueblo para construir una frontera en contra de los otros, es decir, justificar la idea de polarización o juego de suma cero: están conmigo o en mi contra. Ortega proviene de una clase socioeconómica baja, Correa de una media, mientras que Bukele de una alta clase socioeconómica. Eso no agota la capacidad que tuvieron estos líderes para apropiarse de una retórica 
popular y proclamarse como auténticos representantes de la mayoría de la población.

No se puede perder de vista que este artículo analiza un momento concreto de la trayectoria de los líderes, el que más se acerca a encontrar similitudes, pues Ortega tiene a su haber cuatro mandatos constitucionales, Bukele está en el primero y Correa permaneció por una década ininterrumpida en el poder, situación única en Ecuador. También se debe tomar cierta distancia en términos ideológicos, pues Ortega y Correa se autoproclaman progresistas de izquierda, mientras que Bukele es pragmático al tratar de superar en el discurso la diada izquierda-derecha. Eso da cuenta de que el populismo, como estrategia, no es ideológico, lo que le permite moverse según sus intereses.

La legitimidad política de origen de los tres mandatarios que se analiza es diferente. El populismo no tiene como un elemento constitutivo ni tampoco determinístico la procedencia del líder (militar, académica, gremial, militancia partidista), más bien, sobresale en Ortega, Correa y Bukele la construcción identitaria que pretende sintonizar con el pueblo y representarlo desde una idea fuerza de reivindicación histórica y única alternativa de respuesta al statu quo. En Ortega, se observa la configuración de una identidad política de redentor/revolucionario, en Correa del outsiderlantisistema y, en Bukele, la de renegado/disidente del mismo sistema político en el cual construyó su carrera.

La ritualidad que construyen los tres mandatarios alrededor de actos públicos de fe y una retórica elaborada de cristianismo desde sus propias subjetividades, les coloca en el lado más conservador de la política, pese a que se autodenominan "revolucionarios" y contrarios al sistema tradicional de partidos. Hay una liturgia de conexión con el pueblo, apelando a su religiosidad, ya que en los tres países la fe es un elemento identitario de la mayoría de la población. En ese sentido, este tipo de liderazgo populista se apega a los valores más sedimentados del pueblo y de corte colonialista.

En los tres casos, la emergencia populista capitalizó el momento de crisis que atravesaba cada país en lo político. Desde el sistema tradicional de partidos, no hubo un legítimo contradictor y más bien se dejó llevar a un escenario de desgaste acelerado e intenso: declive y desaparición. Ortega edificó su liderazgo como una figura comprometida con el cambio (la democracia), Correa con la reinvención del sistema partidista desde una revolución protagonizada por la ciudadanía y Bukele apeló al enfrentamiento abierto contra los protagonistas tradicionales de la política. El guion es común en los tres presidentes, debido a la idea de cambio con sus propios matices y contextos.

Tras destacar las diferencias entre las figuras de Correa, Ortega y Bukele, podemos observar las semejanzas en el contexto durante su elección a la presidencia. Como antes se señaló, sus elecciones se dan en una coyuntura de "hartazgo político" por parte de la población, la cual parece que permitió que cada uno de estos se colocara como una propuesta electoral viable, a 
pesar de sus diferencias ya señaladas. En los tres casos analizados, menos del $60 \%$ de la población manifiesta apoyar la democracia, y en El Salvador este apoyo lo brinda solo el $28 \%$ de la población. Además, en los tres la población muestra una alta percepción de la corrupción en el funcionamiento de sus gobiernos (ver tabla 3 ).

En cuanto a la calidad de los procesos electorales, el indicador de gobierno representativo, elaborado por el Instituto Internacional para la Democracia y la Asistencia Electoral (IDEA), evidencia que tanto Nicaragua y El Salvador muestran una calificación media, en contraste con Ecuador que poseía una calificación alta al momento de la elección de Rafael Correa (ver tabla 3). Asimismo, el abstencionismo en los procesos electorales en los casos de estudio es medio-alto, con valores cercanos o superiores al $30 \%$; El Salvador es el país con mayor abstencionismo, ya que más de un $48 \%$ del electorado no se presentó a votar en el 2019 (ver tabla 3). Asimismo, en los tres casos, los datos muestran una alta volatilidad electoral, lo que es consecuente con el "cansancio o hartazgo" del electorado con las agrupaciones políticas que gobernaban sus países, con porcentajes mayores al $35 \%$. En este caso, también El Salvador muestra el porcentaje más alto: $53.87 \%$ (ver tabla 3).

Este descontento hacia la política y los grupos políticos tradicionales, y al régimen que en cada país ha funcionado bajo la etiqueta de "democracia", parece fundamentarse en la falta de respuestas y propuestas adecuadas para mejorar la calidad de vida de la población. Como muestra la tabla 3, al momento de su elección, en los tres casos analizados la población que vivía en condición de pobreza era cercana o superior al $30 \%$; al mismo tiempo, el coeficiente de Gini muestra una tendencia hacia la desigualdad en el ingreso.

Por lo tanto, la evidencia recopilada parece sugerir que son las condiciones sociopolíticas: descontento hacia la política y los grupos políticos tradicionales, bajo apoyo a la democracia, alto porcentaje de la población en condición de pobreza y desigual distribución de los ingresos, lo que facilitó a esta figuras políticas a posicionarse como opciones atractivas en los procesos electorales, más allá de las particularidades de su trayectoria política y diferencias ideológicas en sus propuestas de Gobierno. Por lo tanto, se confirma lo ya expuesto en otros trabajos respecto a que los gobiernos populistas surgen y se consolidan en situaciones de exclusión social, polarización política y crisis institucional, ya que en estos es donde la población parece encontrar en la figura del líder populista, independientemente de su ideología, características personales y trayectoria política, una respuesta atractiva para salir de la situación de "hartazgo político" en la que se encuentran (Borón 2012; Ulloa-Tapia 2017).

Sin embargo, el hecho de que liderazgos populistas con características tan distintas logren posicionarse electoralmente de forma exitosa, debido a las condiciones sociopolíticas, abre otra serie de preguntas que requieren ser abordadas en futuros trabajo. Ni Correa, ni Ortega ni Bukele son los primeros políticos y, posiblemente, tampoco serán los últimos, que se apoyan en el populismo para conseguir el apoyo del electorado en sus respectivos países; 
sin embargo, a diferencia de ellos, otros políticos que podrían ser clasificados como populistas no logran el apoyo requerido para ganar las elecciones.

Por lo tanto, las características particulares de su liderazgo les permitirá diferenciarse de otras opciones populistas y mostrarse, de forma atractiva, ante el electorado. No obstante, para corroborar esta suposición, se requiere contrastar los diferentes tipos y características de los políticos populistas a lo interno de cada país, con el propósito de identificar cuáles características y posturas populistas resultan más atractivas a la población.

\section{Bibliografía}

Almeida, Paul. 2016. Neoliberalismo y movimientos populares en Centroamérica. El Salvador: UCA Editores.

Arriola, Jonathan. 2009. "Populismo latinoamericano: El caso de Daniel Ortega en Nicaragua". Letras Internacionales, núm. 75-3 (septiembre). https://revistas.ort.edu.uy/letras-internacionales/article/view/1800.

Bijukumar, V. 2004. "Economic reforms, populism and party politics in India". The Indian Journal of Political Science 65 (2): 161-80.

Blandón Gadea, María Teresa. 2006. "Preguntas al nuevo gobierno desde el feminismo". Revista Envío. https://www.envio.org.ni/articulo/3427.

Blassnig, Sina, y Dominique S. Wirz. 2019. "Populist and Popular: An Experiment on the Drivers of User Reactions to Populist Posts on Facebook". Social Media + Society. https://www.researchgate.net/publication/337511996_Populist_and_Pop ular_An_Experiment_on_the_Drivers_of_User_Reactions_to_Populist_ Posts_on_Facebook.

Borón, Atilio. 2012. “¿Una nueva era populista en América Latina?” En El eterno retorno al populismo en América Latina y el Caribe, 1ª 440. Bogotá: Editorial Pontificia Universidad Javeriana.

Bretón Solo de Zaldívar, Víctor, David Cortez, y Fernando García Serrano. 2014. "En busca del sumak kawsay: presentación del Dossier". Íconos: Revista de Ciencias Sociales, núm. 48: 9-24.

Bueno Romero, Gildardo Antonio. 2013. "El populismo como concepto en América Latina y en Colombia". Estudios Políticos 42: 112-37.

Bugaric, Bojan, y Alenka Kuhelj. 2018. "Varieties of Populism in Europe: Is the Rule of Law in Danger?" Hague Journal of the Rule of Law 10 (1): 2133. https://doi.org/10.1007/s40803-018-0075-4.

Burbano de Lara, Felipe. 1998. El populismo fantasma del: aproximación a un tema (siempre) actual. Quito. 
2005. "Coaliciones fantasmas, esencialismos políticos y corrupción". Iconos. Revista de Ciencias Sociales, núm. 21: 105-12.

Cannon, Barry. 2018. "Must We Talk about Populism? Interrogating Populism's Conceptual Utility in a Context of Crisis". New Political Science $40 \quad 477-96$. https://doi.org/10.1080/07393148.2018.1487187.

Conaghan, Catherin. 2003. "Políticos versus Partidos: discordia y desunión en el sistema de partidos ecuatoriano". En emocracia, gobernabilidad y cultura política. Quito: FLACSO-Ecuador.

Corporación Latinobarómetro. 2006. “Informe Latinobarómetro 2006”. Corporación Latinobarómetro.

—. 2007. "Informe Latinobarómetro 2007”. Corporación Latinobarómetro.

Cuvi, Pablo. 2007. Velasco Ibarra: el último caudillo de la oligarquía. Quito: Eskeletra E.

Deutsche Welle. 2020. "Bukele y su gobierno son la principal fuente de desinformación en el país". DW.COM, el 4 de octubre de 2020. https://www.dw.com/es/bukele-y-su-gobierno-son-la-principal-fuente-dedesinformaci\%C3\%B3n-en-el-pa\%C3\%ADs/a-55153285.

Di Tella, Torcuato S. 1965. "Populismo y Reforma en América Latina". Desarrollo Económico 4 (16): 391-425. https://doi.org/10.2307/3465879.

Dockterman, Eliana, Feliz Solomon, Ioan Grillo, Katy Steinmetz, Cady Lang, Charlotte Alter, Alice Park, Simon Shuster, Tara John, y Kate Samuelson. 2017. "Next Generation Leaders". TIME Magazine 189 (9): 38-47.

El Faro. 2020. "Bukele Amenaza al Periodismo". El Faro, el 30 de julio de 2020, sec. Editorial. https://elfaro.net/es/202007/columnas/24691/Bukele-amenaza-alperiodismo.htm.

Ellner, Steve. 2012. "The Distinguishing Features of Latin America's New Left in Power: The Chávez, Morales, and Correa Governments". Latin American Perspectives 39 (1): 96-114.

Equipo Nitlápan-Envío. 2006a. "Daniel Ortega Presidente: del poder 'desde abajo' al gobierno”. Revista Envío, 2006. https://www.envio.org.ni/articulo/3418.

- 2006b. "La clave: Una derecha dividida política y socialmente". Revista Envío, 2006. https://www.envio.org.ni/articulo/3419.

Fernández Mateo, Joaquín. 2012. "Discurso político: nominación, populismos, identidad política”. En . Madrid. 
Freidenberg, Flavia, y Manuel Alcántara. 2001. Los dueños del poder: los partidos políticos en Ecuador, (1978-2000). Atrio. Quito: FLACSOEcuador.

Freidenberg, Flavia, y Simón Pachano. 2016. El sistema político ecuatoriano. Atrio. Quito: FLACSO-Ecuador.

Galito, Maria Sousa. 2018. "Populism as a Political Phenomenon". Janus.Net: e-Journal of International Relations 9 (1): 53-69. https://doi.org/10.26619/1647-7251.9.1.4.

Germani, Ginno. 1962. Política y sociedad en una época de transición. Argentina: Paidós.

Ghitis, Frida. 2019. “Bukele's Election Represents a New Era in El Salvador-and a Chance for Trump". World Politics Review (Selective Content), febrero, 1-4.

- 2020. "El Salvador Knew Bukele Was Brash. But His Military Show of Force Was Ominous". World Politics Review (Selective Content), febrero, 1-1.

Gooren, Henri. 2010. "Ortega for President: The Religious Rebirth of Sandinismo in Nicaragua". Revista Europea de Estudios Latinoamericanos y del Caribe / European Review of Latin American and Caribbean Studies, núm. 89: 47-63.

Gratius, Susanne. 2009. "Reflexiones sobre la izquierda y el populismo en América Latina”. 6. Colección de Estudios Internacionales. Bilbao: Universidad del País Vasco.

Guzmán, Valeria. 2020. "Bukele Anuncia En Cadena Nacional Que Hacienda Investiga a El Faro Por Lavado de Dinero". El Faro, el 25 de septiembre de 2020, sec. Política. https://elfaro.net/es/202009/el_salvador/24855/Bukele-anuncia-encadena-nacional-que-Hacienda-investiga-a-El-Faro-por-lavado-dedinero.htm.

Hernández, Ivo, y Héctor Hurtado. 2010. El Populismo. Una aproximación a un problema de las democracias de todos los tiempos. Vol. 156. Cuadernos de Ciencias Sociales. San José: FLACSO-Costa Rica.

Hernández-Anzora, Marlon. 2016. "Las maras y la nueva guerra salvadoreña | Nueva Sociedad". Nueva Sociedad. Nueva Sociedad | Democracia y política en América Latina. el 26 de mayo de 2016. https://nuso.org/articulo/las-maras-y-la-nueva-guerra-salvadorena/.

Hodges, Adam. 2019. “How Trump's Populism Shapes the Uptake of New Social Facts". American Anthropologist 121 (1): 185-87. https://doi.org/10.1111/aman.13190.

Huntington, Samuel P. 1993. The Third Wave: Democratization in the Late Twentieth Century. Oklahoma: Univ. of Oklahoma Press. 
Hurtado, Osvaldo. 1998. El poder político en el Ecuador. Colección País de la mitad. Quito: Ariel: Planeta-Letraviva.

Ianni, Octavio. 1980. La formación del Estado Populista en América Latina. México DF: Serie Popular Era.

IDEA. 2020. "The Global State of Democracy Indices". 2020. https://www.idea.int/gsod-indices/\#/indices/world-map.

Jansen, Robert S. 2011. "Populist Mobilization: A New Theoretical Approach to Populism". Sociological Theory 29 (2): 75-96.

Judis, John B. 2018. La explosión populista. Como la Gran Recesión transformó la política en Estados Unidos y Europa. Barcelona: Ediciones Deusto.

Kampwirth, Karen. 2009. "Feminismo, anti-feminismo y la lucha del aborto terapéutico: la memoria y las consecuencias inesperadas de la revolución". En Nicaragua y el FSLN (1979-2009): ¿qué queda de la revolución?, 2009, ISBN 978-84-7290-457-6, págs. 83-115, 83-115. Edicions Bellaterra. https://dialnet.unirioja.es/servlet/articulo? codigo $=4743315$.

Lobo, Tomás. 2020. "Bukele, otro presidente con Dios en su gabinete". Diario Digital Nuestro País, el 5 de junio de 2020. https://www.elpais.cr/2020/06/05/bukele-otro-presidente-con-dios-ensu-gabinete/.

Lynch, Frederick R. 2019. “'How Did this Man Get Elected?' Perspectives on American Politics, Populism and Donald Trump". Society 56 (3): 290-94. https://doi.org/10.1007/s12115-019-00366-5.

Malamud, Carlos, y Rogelio Núñez. 2019. "Elecciones en El Salvador (2019): un fiel reflejo del momento político latinoamericano - Elcano". Real Instituto Elcano. el 31 de enero de 2019. http://www.realinstitutoelcano.org/wps/portal/rielcano_es/contenido? WCM_GLOBAL_CONTEXT=/elcano/elcano_es/zonas_es/ america+latina/ari13-2019-malamud-nunez-êlecciones-el-salvador-fielreflejo-momento-politico-latinoamerica.

Marroquín, Amparo, Julissa Menjivar, y Sofia Ramirez. 2020. "El presidente, el ungido. Nayib Bukele o la instalación de una fac(k)e-cracia creyente". En Fakecracia: Memes y dioses en América Latina, editado por Matías Ponce y Omar Rincón. Editorial Biblos.

Martí I Puig, Salvador. 2008. "El regreso de Ortega: los primeros pasos de su segunda administración”. Revista de ciencia política (Santiago) 28 (1): 287-303. https://doi.org/10.4067/S0718-090X2008000100014.

\footnotetext{
—. 2016. "Nicaragua: Desdemocratización y caudillismo". Revista de ciencia política (Santiago) $36 \quad$ (1): 239-58. https://doi.org/10.4067/S0718-090X2016000100011.
} 
Mejía, Andrés. 2002. "Partidos políticos: el eslabón perdido de la representación". En Gobernabilidad democrática, Sistema Electoral y Pugan de Poderes en Ecuador (1978-1998). Quito: Fundación KonradAdenauer.

Mejía, Andrés. 2009. Por el ojo de una aguja: la formulación de políticas públicas en el Ecuador. Quito: FLACSO-Ecuador.

Menéndez-Carrión, Amparo. 1986. La conquista del voto. De Velasco a Roldós. Quito: Corporación Editora Nacional.

Miranda, Mauricio, e Ivania Álvarez. 2016. “Un enigma llamado Daniel Ortega | Nueva Sociedad". Nueva Sociedad, 2016. https://nuso.org/articulo/unenigma-llamado-daniel-ortega/.

Mizrahi, Darío. 2019. "Populismo millennial: Nayib Bukele y sus dos insólitas semanas de gobierno por Twitter". Infobae, el 15 de junio de 2019. https://www.infobae.com/america/america-latina/2019/06/15/populismomillennial-nayib-bukele-el-presidente-que-lleva-dos-semanasgobernando-por-twitter/.

Montaner, Carlos Alberto. 2020. "Nayib Bukele, el gobernante ungido por la gracia de Dios". El Nuevo Heraldo, el 14 de febrero de 2020. https://www.elnuevoherald.com/opinion-es/opin-col-blogs/carlos-albertomontaner/article240313246.html.

Navas, Albertina. 2020. "Nayib Bukele, ¿el presidente más cool en Twitter o el nuevo populista millenial?" GIGAPP Estudios Working Papers 7 (166182): 529-52.

Nochez, María Luz. 2020. "Los Pastores de Trump También Tientan a Nayib Bukele". El Faro, el 12 de agosto de 2020, sec. Política. https://elfaro.net/es/201908/el_salvador/23555/Los-pastores-de-Trumptambién-tientan-a-Nayib-Bukele.htm.

O'Donnell, Guillermo. 2007. "Hacia un Estado de y para la Democracia”. En 'Democracia/Estado/Ciudadanía. Hacia un Estado de y para la Democracia en América Latina. Lima: PNUD.

Ojeda Segovia, Lautaro. 2013. "El gran ausente. Biografía de Velasco Ibarra". Íconos - Revista de Ciencias Sociales 22. https://doi.org/10.17141/iconos.22.2005.94.

Pachano, Simón. 2011. Calidad de la democracia e instituciones políticas en Bolivia, Ecuador y Perú. Quito: FLACSO-Ecuador.

Paredes Murriagui, María Lorena. 2011. Proceso de cambio político en el Ecuador contemporáneo: un contrapunto con Venezuela. Quito: FLACSO-Ecuador.

Philip, George. 1998. "The new populism, presidentialism and marketorientated reform in Spanish South America". Government \& Opposition 33 (1): 81. 
PNUD. 2003. "Informe sobre el Desarrollo Humano El Salvador (2003)". San Salvador: Programa de las Naciones Unidas para el Desarrollo.

Radio Cable. 2020. “Un año de Nayib Bukele, la 'esperanza milennial' para El Salvador señalada fuera por 'autoritaria' y 'populista'”. Radiocable.com, el 3 de junio de 2020, sec. Actualidad. http://www.radiocable.com/nayibbukele-esperanza-salvador-autoritaria428.html.

Ramírez, Sergio. 1999. Adiós muchachos. Una memoria de la revolución sandinista. Aguilar.

Roberts, Kenneth M. 2007. "Latin America's Populist Revival”. Sais Review 1 (27): 3-15.

Rocha, José Luis. 2016. "El proyecto Ortega-Murillo: cuatro claves de un éxito volátil”. Envío Digital. https://www.envio.org.ni/articulo/5274.

Ruiz-Alba, Noelia, y Rosalba Mancinas-Chávez. 2020. "The communications strategy via Twitter of Nayib Bukele: the millennial president of $\mathrm{El}$ Salvador". Estrategia de comunicación en Twitter de Nayib Bukele: el presidente milenial de El Salvador. 33 (2): 259-75. https://doi.org/10.15581/003.33.2.259-275.

Sánchez Figuera, Rebeca. 2016. "Populismo: ¿definición o indefinición? Utilidad del concepto populismo para describir los nuevos liderazgos en América Latina". Tesis para optar por el grado de Maestría en Estudios Latinoamericanos con Mención en Relaciones Internacionales, Quito: Universidad Andina Simón Bolivar.

Sánchez López, Francisco. 2008. ¿Democracia no lograda o democracia malograda? un análisis del sistema político del Ecuador, 1979-2002. Quito: FLACSO-Ecuador.

Segura, Edwin. 2019. "El Salvador: dos millones de personas viven en pobreza". El Economista, el 2 de julio de 2019, sec. Finanzas. https://www.eleconomista.net/economia/El-Salvador-dos-millones-depersonas-viven-en-pobreza-20190702-0017.html.

Silber, Stefan. 2013. "Refundar Bolivia. La fascinación internacional por Evo Morales y el MAS". Iberoamericana (2001-) 13 (50): 197-208.

Swift, Richard. 2019. "Introducing... Nayib Bukele”. New Internationalist, núm. 519 (junio): 9-9.

Tedesco, Laura, y Rut Diamint. 2014. "Latin American Democracy. What to Do with the Leaders?" Bulletin of Latin American Research 33 (1): 31-45. https://doi.org/10.1111/blar.12070.

Tijerina, Luis, y Laucel Muñoz. 2015. "20 años de reducción de pobreza y desigualdad en El Salvador". Banco Interamericano de Desarrollo. https://publications.iadb.org/publications/spanish/document/20-a \%C3\%B1os-de-reducci\%C3\%B3n-de-pobreza-y-desigualdad-en-ElSalvador.pdf. 
Torre, Carlos de la. 1993. La seducción velasquista. Quito: Ediciones Libri Mundi, Enrique Grosse-Luemern-FLACSO ECUADOR.

—. 2013. "El Tecnopopulismo de Rafael Correa ¿Es compatible el carisma con la tecnocracia?" Latin American Research Review 48 (1): 24-43.

_. 2017. "Trump's populism: lessons from Latin America”. Postcolonial

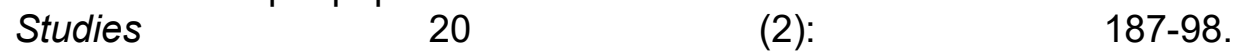
https://doi.org/10.1080/13688790.2017.1363846.

- 2018. "Populism Revived: Donald Trump and the Latin American Leftist Populists". Americas (00031615) 75 (4): 733-53. https://doi.org/10.1017/tam.2018.39.

Turcios, Roberto. 1997. "El Salvador. Una transición histórica y fundacional”. Nueva Sociedad, núm. 150: 112-18.

Ulloa-Tapia, César. 2017. El populismo en escena ¿Por qué emerge en unos países y en otros no? 1'. Quito: FLACSO-Ecuador.

Van Dijk, Teun. 2000. "El discurso como interacción de la sociedad". En El discurso como interacción social. Estudios sobre el discurso II: Una introducción multidisciplinaria, editado por Teun Van Dijk. Barcelona: Gedisa, S. A.

Vásquez, Daniel. 2007. "La democracia, el populismo y los recursos políticos del mercado: déficit democráticos y neopopulismo". En Populismo y Democracia en América LAtina, 319-56. México DF: FLACSO-México.

Verdesoto, Luis. 2014. Los actores y la producción de la democracia y la política en Ecuador 1979-2011. Quito: FLACSO-Ecuador.

Wade, Christine. 2019. "Big Victory Comes With Big Expectations for El Salvador's Young New President". World Politics Review (Selective Content), febrero, 1-4.

Wallace, Arturo. 2020. "Bukele vs El Faro: qué hay detrás del enfrentamiento del popular presidente de El Salvador con uno de los medios más prestigiosos del continente". BBC News Mundo, el 5 de octubre de 2020. https://www.bbc.com/mundo/noticias-america-latina-54408910.

Weber, Max. 1979. El político y el científico. Alianza Editorial. 